Association for Information Systems

AIS Electronic Library (AISeL)

Wirtschaftsinformatik 2021 Proceedings

Track 7: Digital Services and Smart Product-

Service Systems

\title{
Co-Creating Value in B2B Platform Ecosystems - Towards a Deeper Understanding of the Emergence and Nature of Actor Engagement
}

\author{
Carina Benz \\ Karlsruher Institut für Technologie \\ Lara Riefle \\ Karlsruher Institut für Technologie \\ Christoph Schwarz \\ Karlsruher Institut für Technologie
}

Follow this and additional works at: https://aisel.aisnet.org/wi2021

Benz, Carina; Riefle, Lara; and Schwarz, Christoph, "Co-Creating Value in B2B Platform Ecosystems Towards a Deeper Understanding of the Emergence and Nature of Actor Engagement" (2021).

Wirtschaftsinformatik 2021 Proceedings. 5.

https://aisel.aisnet.org/wi2021/TDigitalServices/Track07/5

This material is brought to you by the Wirtschaftsinformatik at AIS Electronic Library (AISeL). It has been accepted for inclusion in Wirtschaftsinformatik 2021 Proceedings by an authorized administrator of AIS Electronic Library (AISeL). For more information, please contact elibrary@aisnet.org. 


\title{
Co-Creating Value in B2B Platform Ecosystems - Towards a Deeper Understanding of the Emergence and Nature of Actor Engagement
}

\author{
Carina Benz ${ }^{1}$, Lara Riefle ${ }^{1}$ and Christopher Schwarz ${ }^{2}$ \\ ${ }^{1}$ Karlsruhe Institute of Technology, Karlsruhe, Germany \\ \{carina.benz, lara.riefle\}@kit.edu \\ ${ }^{2}$ Celonis SE, Munich, Germany \\ c.schwarz@celonis.com
}

\begin{abstract}
Digital platforms (e.g., Industrial Internet of Things (IIoT) platforms) are on the rise aiming to foster value co-creation in business-to-business (B2B) ecosystems. However, we often observe actors to only hesitantly engage, and activity levels that fall short of expectations. Arriving at a sound understanding of why and how actors decide to engage in co-creation practices is a crucial first step to further promote and facilitate value co-creation in B2B platform ecosystems. This work builds upon the concept of actor engagement, which offers an actor-centric microlens on the hitherto vague theoretical idea of value co-creation. By pursuing a qualitative approach to theory development based on interviews with platform complementors, we identify factors influencing the formation and extent of actor engagement. Eventually, our research aims to contribute to a refined conception of value co-creation in B2B platform ecosystems by understanding the emergence and nature of actor engagement.
\end{abstract}

Keywords: actor engagement, value co-creation, B2B platform ecosystem

\section{Introduction}

Along with the introduction of the service-dominant logic (SDL) - proclaiming that value is always co-created, i.e., a result from the interaction and resource integration within service ecosystems [1] — we observe increased efforts in industry to foster cocreation practices. Recently, digital platforms gain ground as means to foster value cocreation in service ecosystems [2, 3]. Also, Lusch and Nambisan [2] acknowledge the role of platforms in facilitating the interaction of actors and easing access to appropriate resource bundles, thus reflecting an instrument to enhance the effectiveness and efficiency of value co-creation. Following impressive success stories of platforms and value co-creation among different actors produced by the business-to-consumer (B2C) sector (e.g., AirBnB, Apple's App Store), the industrial sector is just beginning to tap their potential. One example of such digital platforms in B2B ecosystems are Industrial Internet of Things (IIoT) platforms, which e.g., enable the provision of digital services in the industrial sector based on machine data [4]. 
Yet, academic knowledge on B2B platform ecosystems is currently still unfolding. Concentrating on the formation of platform ecosystems in industry [5-7], their design, government, and boundary resources $[8,9]$, or the platform owner's role $[10,11]$, the majority of current studies is strongly platform-focused. Less considered are actor roles apart from the platform owner. In particular, the perspective of platform complementors - i.e., actors who offer their value proposition (e.g., digital services) via the platform [12] - is still unrepresented, though significantly contributing to the platforms' attractiveness $[9,13,14]$. Equally, a platform's operating phase succeeding the initial launch and joining of actors is less in focus. This, however, is when resources will be shared and integrated, and the co-creation of value will proceed [15]. The same lack of attention can also be observed in practice: B2B platforms are being launched and established, but activity of complementors is limited and collaboration with customers is only approached hesitantly [14]. Hence, academic and practical knowledge on value co-creation in B2B platform ecosystems is still unfolding and requires a deeper understanding of why and how actors in B2B platform ecosystems engage in co-creation practices $[16,17]$.

The idea of exploring actors' engagement as the lowest observational level of value co-creation in service ecosystems has been recently brought to the discourse by Storbacka et al. [18]. Adopting the theoretical perspective of actor engagement [18] allows bridging the gap between the vague and elusive concept of value co-creation on a macro level and an actor's observable behavior on a micro level $[19,20]$. Defined as "both the actor's disposition to engage, and the activity of engaging in an interactive process of resource integration within a service ecosystem" [18, p. 308] actor engagement is recognized as microfoundation for value co-creation and midrange concept in the SDL [21]. However, research on engagement in B2B contexts is only just emerging and knowledge on how engagement advances within service ecosystems of organizational actors is still scarce [22,23].

With this research, we aim to contribute towards a refined conception of value cocreation in B2B platform ecosystems by understanding the emergence and nature of actor engagement. Specifically, we seek to explore factors that influence the formation and intensity of actor engagement among complementors in B2B platform ecosystems [18]. We, therefore, pursue a qualitative and inductive approach to theory development based on interviews with platform complementors. In doing so, we not only provide practical insights on determinants for complementors' motivation to grow, stay and engage in B2B platform ecosystems, but contribute to a refined conceptualization of actor engagement as microfoundation of value co-creation.

The remainder of this paper is structured as follows: Section 2 briefly introduces the fundamentals of actor engagement and highlights related work. Section 3 outlines our research approach, while Section 4 presents initial findings. Section 5 provides an outlook and summarizes our expected contribution. 


\section{$2 \quad$ Fundamentals}

Service science is centered on the concept of value co-creation within and among service ecosystems [24]. It builds upon the service-dominant logic (SDL), which declares that value is always co-created, i.e., that value results from the interaction and resource integration of multiple actors for mutual benefit [1]. Yet, scholars agree that the SDL view on value co-creation is still too abstract to be empirically observable $[18$, $19,25]$. With the concept of actor engagement, Storbacka et al. [18] address the need for a more nuanced perspective on value co-creation $[19,26]$. Informed by the microfoundation movement [27], actor engagement follows the idea that collective phenomena can only be captured when examining their constituent parts on an actor level [18]. In a three-level model, (1) the abstract idea of value co-creation in service ecosystems on a macro level is broken down into (2) the meso level view of actors and resources that exercise resource integration patterns facilitated by engagement platforms, and (3) the actor engagement on the micro level (Figure 1). Actor engagement subsumes both, the actor's disposition and engagement properties. Actor disposition reflects the actor's willingness to invest resources in their interaction with other actors [28], which is "formed partly by actor specific characteristics and partly by the institutional and organizational arrangements prevalent in the context in which the resource contributions occur" [29, p. 6] (e.g., the willingness to join a platform). Engagement properties, in turn, refer to observable engagement activities (e.g., sharing of resources, provisioning of services) [13, 18]. Analogous to the transformation of human intention to behavior in psychology, actor dispositions may translate into observable engagement properties through an action-formation mechanism [18, 30]. The role of an actor generally is generic, hence it can be taken by a single actor (human or machine) as well as a group of actors (collectives or organizations) [22, 29].

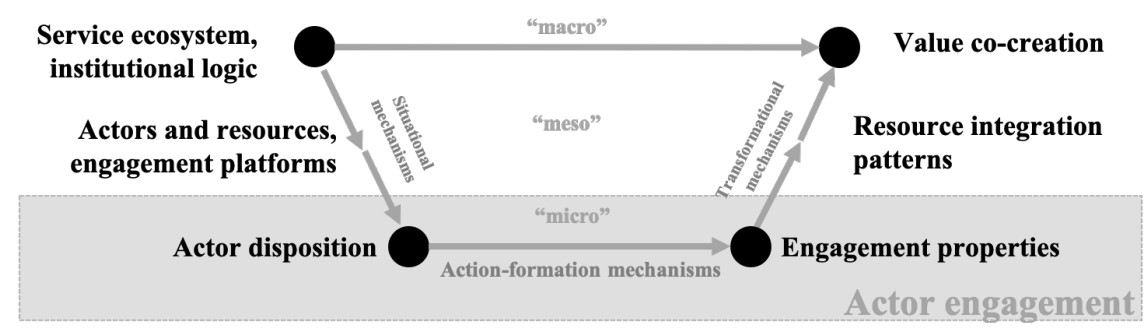

Figure 1. Actor engagement as microfoundation for value co-creation [18]

Apart from conceptual work, there are empirically driven initiatives to understand value co-creation in B2B platform ecosystems: Hein et al. [15] identify three standard types of co-creation practices in IoT ecosystems: integration of complementary assets, ensuring of platform readiness, and servitization through application enablement. A platform owner's ability to ensure the effective and efficient operation of these cocreation practices is recognized as a prerequisite for platform survival by Blaschke et al. [8]. Also, there is initial research aiming to understand complementors' motivation to join a digital platform ecosystem $[7,9,14]$. 


\section{$3 \quad$ Research Approach}

Our objective is to refine the understanding of actor engagement of complementors in B2B platform ecosystems. To account for the exploratory and inductive nature of our research goal, we adopt a qualitative research approach following Strauss and Corbin [31]. As a starting point, an IIoT platform for the process industry ecosystem hosted by a multinational software corporation serves as a locus for data collection. Data is collected in the form of semi-structured interviews conducted with complementors (e.g., machine manufacturers and service providers) of the IIoT platform. The selection of interview partners follows a theoretical sampling approach, i.e., interview partners are selected based on theoretical relevance assessed through emerging concepts from the analysis of previous interviews [31,32]. An overview of the interviews conducted so far is provided in Table 1. The interviews are iteratively analyzed in three coding cycles - open, axial, and selective - according to the Straussian approach [31]. After each analysis cycle, the results are discussed by two independent researchers to rule out discrepancies in coding and to collaboratively evolve the emerging concepts [33].

Table 1. Preliminary overview of interviews

\begin{tabular}{lllll}
\hline Interviewee & Firm & Employees & Industry & Role \\
\hline Alpha & A & $1.000-5.000$ & Manufacturing & Integrator \& User \\
Beta & B & $1.000-5.000$ & Manufacturing & Integrator \& User \\
Gamma & C & $10.000-50.000$ & Automation & Integrator \\
Delta & D & $1.000-5.000$. & Industrial Service & Strategic Lead \\
Epsilon & A & $1.000-5.000$. & Manufacturing & Strategic Lead \\
Zeta & E & $10.000-50.000$ & Automation & Strategic Lead \\
\hline
\end{tabular}

\section{$4 \quad$ Initial Findings}

With our research endeavor still being in progress, we provide preliminary insights into two concepts in emergence: partner engagement behavior and value realization (Figure 2). Partner engagement behavior reflects the extent of engagement properties of an actors' potential counterparts for value co-creation. These counterparts can be potential customers or implementation partners, including the platform owner. Interviewee Zeta, whose company has recently scaled down their activities on the platform states: "We have invested a lot of time and money to be ready. But we cannot do more than that $[\ldots]$ if there isn't a single one of our customers [...] to use it productively" (Zeta). In contrast, other actors' effort and commitment in co-implementing new use cases is positively related to the formation of engagement properties: "A requirement is the willingness to work together on concrete topics at eye level— despite a clear difference in size between operators and manufacturers - and the commitment to work on this as partners" (Beta). Our concept of partner engagement behavior is also in line with conceptual research proposing that engagement manifests through behaviors, whereby actors in an ecosystem influence each other's dispositions and behaviors [21, 23]. 
Value realization refers to the extent of benefits that an actor recognizes to leverage from engaging in the platform ecosystem. We observe the participation in a B2B platform ecosystem to be associated with high expectancies related to access to other actors' data and the provision of novel digital services (Epsilon, Gamma). At the same time, it requires high upfront effort combined with vague benefit prospects, as Epsilon states: "One must recognize the benefits, even if these rather lie in the future" (Epsilon). Hence, noticing that engagement activities are leading to - even small-observable benefits is decisive for continuous engagement. Consequently, engaged interviewees report on a clear potential to realize monetary returns: "This means that the end customer is already willing to pay money for this data. [...] We just have to redirect it" (Beta), or internal efficiency improvements: "We also had to work out the benefits ourselves. We were able to find use cases for ourselves, internally; for our own service technicians" (Alpha). This complements previous empirical research in B2C contexts that finds rewards and recognition to encourage customer engagement $[34,35]$.

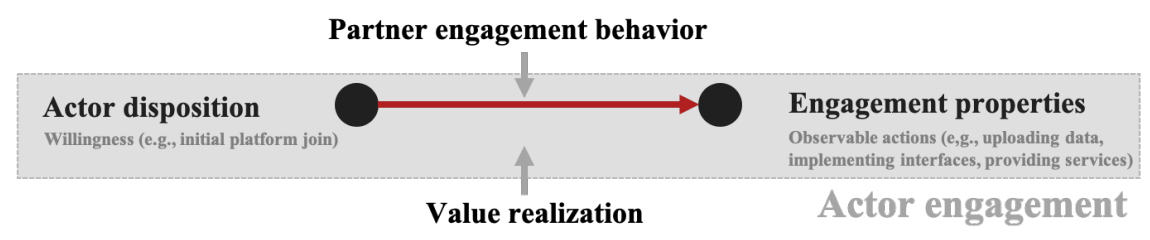

Figure 2. Partner engagement behavior and value realization as emerging concepts

\section{Outlook and Conclusion}

Aiming to understand the emergence and nature of actor engagement as microfoundation for value co-creation in B2B platform ecosystems, we pursue a qualitative approach to theory development. With our sampling strategy being driven by the objective of theoretical saturation, future interviews will be iteratively reassessed, guided by previous findings. As of now, we see the need for subsequent interviews to account for interviewees with above- and below-average engagement and to incorporate companies with different levels of vertical integration.

Upon completion, our results will contribute to research in the field of service science and digital platforms. In the broadest sense, our study will contribute to service theory by following Grönroos and Voimas' [19] call for a theoretically sound foundation for value co-creation. In particular, we adopt the concept of actor engagement [18] to study value co-creation in B2B platform ecosystems on the micro level of an actor's intention and activities. In observing how individual actors assimilate contextual conditions into actions, we refine the understanding of actor engagement and contribute to theory building in this emerging field of research. From the perspective of digital platform research, our contribution arises from offering new insights into the antecedents and evolution of complementors' engagement in B2B platform ecosystems. This knowledge may empower practitioners and platform designers to foster and maintain engagement within their platform ecosystems. 


\section{References}

1. Vargo, S.L., Lusch, R.F.: Evolving to a New Dominant Logic for Marketing. J. Mark. 68, 1-17 (2004).

2. Lusch, R.F., Nambisan, S.: Service Innovation: A Service-Dominant Logic Perspective. MISQ. 39, 155-175 (2015).

3. De Reuver, M., Sørensen, C., Basole, R.C.: The digital platform: a research agenda. J. Inf. Technol. 33, 124-135 (2017).

4. Petrik, D., Herzwurm, G.: iIoT Ecosystem Development through Boundary Resources: A Siemens MindSphere Case Study. In: IWSiB '19. Tallinn, Estonia (2019).

5. Staykova, K.S.: Managing Platform Ecosystem Evolution through the Emergence of Micro-strategies and Microstructures. In: Proceedings of the 39th International Conference on Information Systems (ICIS). San Francisco, CA, USA (2018).

6. Hein, A., Schreieck, M., Wiesche, M., Böhm, M., Krcmar, H.: The emergence of native multi-sided platforms and their influence on incumbents. Electron. Mark. 29, 631-647 (2019).

7. Petrik, D., Herzwurm, G.: Towards the iIoT Ecosystem Development-Understanding the Stakeholder Perspective. In: Proceedings of the 28th European Conference on Information Systems (ECIS). An Online AIS Conference (2020).

8. Blaschke, M., Aier, S., Haki, K., Winter, R.: Capabilities for digital platform survival: Insights from a business-to-business digital platform. In: Proceedings of the 39th International Conference on Information Systems (ICIS). San Francisco, CA, USA (2018).

9. Petrik, D., Herzwurm, G.: Complementor Satisfaction with Boundary Resources in IIoT Ecosystems. In: Proceedings of the 23rd International Conference on Business Information Systems. pp. 351-366. Colorado Springs, CO, USA (2020).

10. Mini, T., Widjaja, T.: Tensions in Digital Platform Business Models: A Literature Review. In: Proceedings of the 40th International Conference on Information Systems (ICIS). Munich, Germany (2019).

11. Hein, A., Setzke, D.S., Hermes, S., Weking, J.: The influence of digital affordances and generativity on digital platform leadership. In: Proceedings of the 40th International Conference on Information Systems (ICIS). Munich, Germany (2019).

12. Kapoor, R.: Ecosystems: broadening the locus of value creation. J. Organ. Des. 7, (2018).

13. Hein, A., Schreieck, M., Riasanow, T., Setzke, D.S., Wiesche, M., Böhm, M., Krcmar, H.: Digital platform ecosystems. Electron. Mark. 30, 87-98 (2020).

14. Pauli, T., Marx, E., Matzner, M.: Leveraging Industrial IoT Platform Ecosystems: Insights from the Complementors' Perspective. In: Twenty-Eighth European Conference on Information Systems (ECIS). An Online AIS Conference (2020).

15. Hein, A., Weking, J., Schreieck, M., Wiesche, M., Böhm, M., Krcmar, H.: Value cocreation practices in business-to-business platform ecosystems. Electron. Mark. 29, 503-518 (2019).

16. Jonas, J.M., Boha, J., Sörhammar, D., Moeslein, K.M.: Stakeholder engagement in intraand inter-organizational innovation: Exploring antecedents of engagement in service ecosystems. J. Serv. Manag. 29, 399-421 (2018). 
17. Gelhaar, J., Otto, B.: Challenges in the emergence of data ecosystems. In: Proceedings of the 24th Pacific Asia Conference on Information Systems (PACIS). Dubai, UAE (2020).

18. Storbacka, K., Brodie, R.J., Böhmann, T., Maglio, P.P., Nenonen, S.: Actor engagement as a microfoundation for value co-creation. J. Bus. Res. Journal of, 3008-3017 (2016).

19. Grönroos, C., Voima, P.: Critical service logic: making sense of value creation and cocreation. J. Acad. Mark. Sci. 41, 133-150 (2013).

20. Grotherr, C., Semmann, M., Böhmann, T.: Using microfoundations of value co-creation to guide service systems design - A multilevel design framework. In: Proceedings of the 39th International Conference on Information Systems (ICIS). San Francisco, CA, USA (2018).

21. Alexander, M.J., Jaakkola, E., Hollebeek, L.D.: Zooming out: actor engagement beyond the dyadic. J. Serv. Manag. 29, 333-351 (2018).

22. Kleinaltenkamp, M., Karpen, I.O., Plewa, C., Jaakkola, E., Conduit, J.: Collective engagement in organizational settings. Ind. Mark. Manag. 80, 11-23 (2019).

23. Fehrer, J.A., Conduit, J., Plewa, C., Li, L.P., Jaakkola, E., Alexander, M.: Market shaping dynamics: interplay of actor engagement and institutional work. J. Bus. Ind. Mark. (2020).

24. Vargo, S.L., Akaka, M.A.: Value Cocreation and Service Systems (Re)Formation: A Service Ecosystems View. Serv. Sci. 4, 207-217 (2012).

25. Schüritz, R., Farrell, K., Wixom, B., Satzger, G.: Value Co-Creation in Data-Driven Services: Towards a Deeper Understanding of the Joint Sphere. In: Proceedings of the 40th International Conference on Information Systems (ICIS). Munich, Germany (2019).

26. Vargo, S.L., Lusch, R.F.: Institutions and axioms: an extension and update of servicedominant logic. J. Acad. Mark. Sci. 44, 5-23 (2016).

27. Felin, T., Ployhart, R.E.: The Microfoundations Movement in Strategy and Organization Theory. Acad. Manag. Ann. 9, 575-632 (2015).

28. Brodie, R.J., Fehrer, J.A., Jaakkola, E., Conduit, J.: Actor Engagement in Networks: Defining the Conceptual Domain. J. Serv. Res. 22, 173-188 (2019).

29. Storbacka, K.: Actor engagement, value creation and market innovation. Ind. Mark. Manag. 80, 4-10 (2019).

30. Ajzen, I.: The Theory of Planned Behavior. Organ. Behav. Hum. Decis. Process. 50, 179-211 (1991).

31. Corbin, J.M., Strauss, A.L.: Basics of qualitative research: techniques and procedures for developing grounded theory. Sage, Los Angeles, Calif. (2015).

32. Halaweh, M., Fidler, C., McRobb, S.: Integrating the Grounded Theory Method and Case Study Research Methodology Within IS Research : A Possible ' Road Map .' In: Proceedings of the Twenty Ninth International Conference on Information Systems (ICIS). Paris, France (2008).

33. Gioia, D.A., Corley, K.G., Hamilton, A.L.: Seeking Qualitative Rigor in Inductive Research: Notes on the Gioia Methodology. Organ. Res. Methods. 16, 15-31 (2013).

34. Chan, T.K.H., Zheng, X., Cheung, C.M.K., Lee, M.K.O., Lee, Z.W.Y.: Antecedents and consequences of customer engagement in online brand communities. J. Mark. Anal. 2, 81-97 (2014). 
35. Jaakkola, E., Alexander, M.: The Role of Customer Engagement Behavior in Value CoCreation: A Service System Perspective. J. Serv. Res. 17, 247-261 (2014). 